\title{
El concepto mimético de la literatura en los textos ensayísticos de Galdós
}

\author{
The mimetic concept of literature in Galdos' essays
}

\begin{tabular}{c} 
AsCENSIÓN RIVAS HERNÁNDEZ \\
\hline Universidad de Salamanca. Salamanca, España. \\
sisina@usal.es
\end{tabular}

\section{RESUMEN}

En este artículo se analizan algunas obras menores de Benito Pérez Galdós, novelas cortas y ensayos anovelados, que recogen aspectos significativos de la poética del novelista canario. El concepto que Galdós tiene de la literatura se encuadra dentro del clasicismo más ortodoxo. Parte el autor de la mímesis, y al relacionarla con el folletín observa que el género no cumple con el precepto porque crea una realidad inexistente. Pero además, el folletín sólo deleita y es un mal ejemplo para la juventud. Por eso lo rechaza Galdós en sus textos, a pesar de que había sido ávido lector del género. Junto a este concepto se analiza la idea del público (más concretamente el vulgo) como elemento de la imitación, y otros aspectos vinculados como la relación entre la literatura y la realidad. En los relatos, además, se observan modelos o técnicas que el novelista canario utiliza en sus grandes textos de ficción, al hilo de los cuales surgen las reflexiones sobre su propia poética.

Palabras claves: Galdós, Aristóteles, teoría poética, mímesis, folletín, público, novela corta, ensayo, realidad y ficción.

\section{ABSTRACT}

In this article there are analysed some Benito Perez Galdós's minor works, short novels and essays, that collect significant aspects of the poetics of the Canary novelist. The 
concept that Galdós has about literature is fitted inside the most orthodox classicism. He starts from the mímesis, and as he relates it to the feuilleton observes that the genre does not achieve with the rule because it creates a non-existent reality. But in addition, the feuilleton only delights and is a bad example for the youth. Because of it Galdós rejects it in his texts, though he had been an eager reader of the genre. Close to this concept there is analysed the idea of the public (more concretly the masses) as element of the imitation, and other aspects like the relation between the literature and the reality. Besides, in the short novels we can observe models and techniques that Canary novelist uses in his novels and at the same time Galdos' reflections about his own poetics.

Keywords: Galdós, Aristóteles, poetic theory, feuilleton, reader, story, essay, reality, fiction.

Recibido: 09-06-2009. Aceptado: 30-11-2009.

urante algún tiempo la crítica defendió la idea de un Galdós despreocupado de la escritura. En este sentido el autor de Fortunata y Jacinta sufrió la misma injusticia que Baroja, de quien siempre se había destacado su desinterés por la composición ${ }^{1}$. Ambos novelistas, dos de los más relevantes entre el último tercio del siglo XIX y el primero del $\mathrm{XX}$, han sido considerados poco menos que ignorantes en materia técnica, escritores que llevaban a cabo su labor sin haber reflexionado sobre el hecho ficcional, sobre su concepto de lo literario y sobre su posición como autores en los textos. Del caso Galdós ha dado cuenta Laureano Bonet en su imprescindible "Introducción" a Ensayos de crítica literaria, dedicados al novelista canario, sobre todo cuando, refiriéndose a la crítica de la Restauración afirma que en términos generales definió a Galdós como autor espontáneo "cuyas novelas surgían del vacío porque sí, sin un proceso previo de intelectualización" (Bonet, 1999: 7). El mismo Bonet recoge unas palabras de Leopoldo Alas en las que éste expresa el desconocimiento galdosiano de la crítica literaria, y se refiere a la espontaneidad de su ingenio:

Tal vez sin pensarlo, me atreveré a decir que sin pensarlo, pues no es de esos novelistas que siguen al día las vicisitudes de la crítica literaria y hacen de sus libros de inspiración programas de tendencias estéticas: Galdós, por impulsos espontáneos de su ingenio, ha recorrido en su larga historia

\footnotetext{
${ }^{1}$ Contra esta idea vid. Ascensión Rivas, 1998.
} 
poética etapas distintas, que corresponden a los grandes movimientos de la literatura moderna (Alas, 1912: 196-197; en Bonet, 1999: 8).

Pero nada más lejos de la realidad, y ahí está el estudio de Laureano Bonet para demostrarlo. De hecho, Galdós se ocupó de cuestiones de técnica y crítica tanto en textos de carácter teórico como en otros de esquema y contenido ficcional, como se tratará de mostrar a lo largo de este artículo.

Aunque en todos los escritos en los que Galdós se refiere a su poética late un mismo concepto general sobre lo literario, existe una clara diferencia entre textos ficcionales y textos ensayísticos tanto en forma como en contenido: los primeros cuentan con una técnica que los vincula al cuento y los segundos carecen de ella; además en los primeros el elemento técnico surge al hilo de la trama literaria mientras en los segundos se manifiesta de forma más abierta. De hecho, al referirse a algunos de estos textos, José Carlos Mainer (2004: Xx) los sitúa sin ambages dentro de la producción literaria del novelista, y los relaciona con una forma concreta de difusión, el periódico, porque no en vano vieron sus primeras luces en las páginas de la prensa. Algunos críticos, incluso, los han estudiado desde una perspectiva exclusivamente literaria, como textos pertenecientes al género "cuento". Así ha sucedido en dos importantes trabajos: el de Alan E. Smith Los cuentos inverosímiles de Galdós en el contexto de su obra (1992) y el de Julio Peñate Rivero Benito Pérez Galdós y el cuento literario como sistema (2001). Como se pone de relieve en éstos y en otros trabajos, algunas de esas obras son, en efecto, cuentos, pero no sólo cuentos o no cuentos sin más, porque en ocasiones nos encontramos ante relatos híbridos que combinan elementos del género con otros propios del artículo de costumbres, la sátira o la literatura de viajes, según ha explicado José Carlos Mainer (2004: xx). El mismo Alan E. Smith reúne algunas de esas piezas bajo una etiqueta común, "En busca del cuento", y entre ellas aparecen algunas de las que se va a tratar aquí, como "La novela en el tranvía", "Un tribunal literario" o "El artículo de fondo".

Uno de los aspectos más significativos de la poética galdosiana es su visión de la literatura como mímesis de la realidad. El concepto fue esgrimido por Aristóteles para explicar una literatura en la que se buscaba ampliar el conocimiento humano más allá de la experiencia². En "Observaciones sobre

\footnotetext{
${ }^{2}$ Por eso, precisamente, la Literatura se consideraba más universal y filosófica que la Historia, con la que entraba en conflicto. La Historia narra lo sucedido pero la Literatura cuenta "lo que podría suceder y lo posible en virtud de la verosimilitud y la necesidad" (1451b, Aristóteles, 2002: 53). Según este concepto la Literatura enriquece la experiencia del hombre porque le permite conocer situaciones a las que nunca va a enfrentarse de manera real y vivir sentimientos que de otra
} 
la novela contemporánea en España" Galdós afirma que la novela de verdad debe ser "espejo fiel de la sociedad en la que vivimos", y que el auténtico novelista debe observar más la realidad e imaginarla menos como ya hicieron Cervantes y Velázquez, dos de nuestros más sublimes artistas. Pero es en "La sociedad presente como materia novelable" donde Galdós expresa con mayor exactitud ese carácter mimético que debe tener la novela. Se trata de su Discurso de ingreso en la Real Academia Española y fue escrito en 1897, casi treinta años después que el primer ensayo y que los relatos ensayísticos que serán comentados aquí. De ahí que Laureano Bonet destaque su importancia como balance de la trayectoria del autor y como reflexión sobre las nuevas formas que la novela empezaba a adoptar en los albores del siglo $\mathrm{XX}^{4}$. En ese texto Galdós habla sobre la mímesis en estos términos:

Imagen de la vida es la Novela, y el arte de componerla estriba en reproducir los caracteres humanos, las pasiones, las debilidades, lo grande y lo pequeño, las almas y las fisonomías, todo lo espiritual y lo físico que nos constituye y nos rodea, y el lenguaje, que es la marca de raza, y las viviendas, que son como signo de familia, y la vestidura, que diseña los últimos trazos externos de la personalidad: todo eso sin olvidar que debe existir perfecto fiel de balanza entre la exactitud y la belleza de la reproducción. (en Mainer, 2004: 107).

El concepto de mímesis que se refleja en este texto es totalizador. La mímesis literaria lo abarca todo: lo físico y lo espiritual, el lenguaje, el modo de vida, hasta los vestidos, porque cualquier elemento puede servir para captar más fielmente la realidad. A pesar de todo, como señala Galdós, es importante conjugar la exactitud y la belleza, es decir, mantener la mímesis evitando al mismo tiempo caer en lo excesivamente grosero. En este caso Galdós aboga por un realismo moderado, alejado del naturalismo más extremo. El novelista tiene que huir de lo que no sea estético porque ha de darse un

manera le estarían vedados. Éste es el principio de la ficcionalidad, que se sustenta en la mímesis. La necesidad y la verosimilitud funcionan como jueces implacables que vigilan el respeto hacia los límites de la ficción.

${ }^{3}$ El artículo se edita por primera vez en Revista de España, 57, el 13 de julio de 1870, pp. 162172.

${ }^{4}$ En este sentido afirma Bonet: "Tal disertación es, sin duda, uno de los escritos teóricos más considerables del autor, y ello tanto por contrastar sin rodeos - casi a treinta años vista- con el programa creativo que Galdós se había impuesto y en trance ya de concluir [...] como, especialmente, por ser meditación sobre la obra cumplida y examen de los nuevos derroteros que la novela posnaturalista estaba tomando al filo del siglo XX" (1999: 59). 
equilibrio perfecto entre la exactitud del dibujo (mímesis) y la belleza. Éste es, pues, para Galdós, el límite de la imitación, mientras para el Estagirita la frontera se situaba en torno a la necesidad y la verosimilitud, según quedó señalado en la nota 1. El mismo Aristóteles se había aproximado en cierto modo a esta idea cuando afirmaba que la tragedia imita a los hombres mejores de lo que son ${ }^{5}$. Aunque tradicionalmente se ha interpretado el pasaje desde el punto de vista moral, lo cierto es que en la traducción de López Eire se introduce un matiz estético que enriquece el sentido del texto y que no sería lícito rechazar.

Además Galdós refuerza su concepto de mímesis cuando compara la literatura con la pintura en lo que supone otra vinculación evidente con la teoría clásica. La idea se remonta a Simónides de Ceos, autor del siglo V a.C. para quien la pintura es poesía silenciosa y la poesía pintura que habla. Pero es Horacio quien recogió la imagen para la historia en la Epistola a los Pisones y la acuñó en la expresión ut pictura poiesis (como la pintura, así la poesía). Galdós la hace suya cuando en el Discurso de ingreso en la Academia se refiere al vulgo como principal objeto de la imitación, y para ello utiliza una alegoría de la pintura, como se observa en estas palabras:

Quiero, pues, examinar brevemente ese natural, hablando en términos pictóricos, que extendido en derredor nuestro, nos dice y aún nos manda que le pintemos, pidiéndonos con ardorosa sugestión su retrato para recrearse en él, o abominar del artista con crítica severa (en Mainer, 2004: 108).

Según ha expresado Galdós, la buena novela tiene que ser un reflejo fiel de la realidad de su tiempo, pero a menudo nos encontramos con textos que incumplen este principio. El público se ha acostumbrado a un tipo de obra que se ha difundido con extraordinaria rapidez desde Francia y que ha alcanzado nuestras fronteras. En estas novelas aparecen personajes estereotipados a los que el lector reconocía sin dificultad ${ }^{6}$. Por ello son fáciles de interpretar y fáciles de elaborar (se originan por medio de moldes), y las únicas que dan dinero y que sostienen a "algunas pequeñas industrias

\footnotetext{
${ }^{5}$ El pasaje de la Poética dice así: "Y puesto que la tragedia es imitación de hombres mejores que nosotros, es menester imitar a los buenos retratistas, pues ellos, efectivamente, aunque reproducen la forma particular de sus modelos tratando de representarlos parecidos, los pintarán más hermosos" (1454b, Aristóteles, 2002: 69).

${ }^{6}$ En "Observaciones sobre la novela contemporánea en España" dice Galdós al respecto: "El público ha dicho: 'Quiero traidores pálidos y de mirada siniestra, modistas angelicales, meretrices con aureola, duquesas averiadas, jorobados románticos, adulterios, extremos de amor y odio', y le han dado todo esto" (en Mainer, 2004: 13).
} 
editoriales" (en Mainer, 2004: 13). Se trata, naturalmente, de la novela de folletín, de la que tanto parece abominar Galdós a lo largo de toda su carrera en textos teóricos y literarios ${ }^{7}$, y cuya lectura ejerce tanta influencia sobre la juventud. La razón de que Galdós rechace el género folletinesco, a pesar de la atracción irracional que había ejercido sobre él desde la infancia, radica en su desvinculación de la realidad, porque, en efecto, el folletín muestra un mundo que sólo existe en la ficción, una sociedad "que hemos conocido en nuestras lecturas" (en Mainer, 2004: 13), pero que no tiene ningún reflejo en la realidad real. Hay, por lo tanto, una "realidad" inventada, puro producto ficcional, que aparece en la novela de folletín, mientras la literatura de verdad, a la que debe tender todo buen escritor como Cervantes o Dickens, es aquélla que está de acuerdo con el concepto de mímesis como imitación de la realidad.

En sintonía con esa formación clásica que se refleja en los ensayos, Galdós señala cómo la literatura folletinesca sólo busca distraer y deleitar al lector, incumpliendo de este modo la máxima horaciana de conjugar el didactismo y el deleite. En este sentido, Galdós relaciona varios aspectos vinculados todos ellos con esa forma de mala literatura, a saber: su carácter estereotipado; el mal ejemplo que ejerce en la sociedad, sobre todo en la juventud; su carácter imaginario; su finalidad sólo deleitosa; y, finalmente, el hecho de estar dirigida a un público muy mayoritario y, por lo tanto, poco escogido, un público, además, de escasos recursos económicos porque se presenta en un soporte -el folletín- accesible, como señala el novelista canario "a las fortunas más modestas" (en Mainer, 2004: 14).

El público es, en efecto, uno de los factores que más preocupa a Galdós. De hecho, nuestro autor reflexiona en profundidad sobre este elemento fundamental de la comunicación literaria en un texto de madurez, el ya mencionado Discurso de ingreso en la Academia. Para Galdós el público es el "autor supremo" de los libros, porque, basándose en su concepto de mímesis, es quien los inspira, mientras el que los escribe recibe la denominación más humilde de "autor inmediato". Y esto es así porque, a su juicio, el público tiene una doble misión -creadora y receptiva- ya que primero inspira las obras y después las juzga como lector:

\footnotetext{
${ }^{7}$ Incluso en las crónicas que escribió para el periódico argentino La Prensa, en las que informaba entre otros asuntos del crimen de la calle de Fuencarral, Galdós se hace eco del carácter inverosímil que va cobrando el relato del suceso en los periódicos españoles, y para ello lo compara de forma peyorativa con las novelas de Ponson du Terrail y de Montepin (Pérez Galdós, 2002: 24). Sobre éste y otros asuntos relacionados con el texto de Galdós, vid. Rivas Hernández, 2007.
} 
[...] al lector inicial de la obra artística, el público, la grey humana, a quien no vacilo en llamar vulgo, dando a esta palabra la acepción de muchedumbre alineada en un nivel medio de ideas y sentimientos; al vulgo, sí, materia primera y última de toda labor artística, porque él, como humanidad, nos da las pasiones, los caracteres, el lenguaje, y después, como público, nos pide cuentas de aquellos elementos que nos ofreció para componer con materiales artísticos su propia imagen: de modo que empezando por ser nuestro modelo, acaba por ser nuestro juez (en Mainer, 2004: 108).

Para Galdós, pues, el público es alfa y omega de la creación literaria porque es fuente de inspiración y juez último en la lectura. Pero en opinión de Galdós, la sociedad contemporánea se está desdibujando porque ya no quedan tipos genuinos, propios de las dos clases sociales de antaño. Ahora aquello se reduce a una clase media mezclada y sin matices, con individuos que tienen rasgos comunes de unos y de otros. El arte de entonces tenía unos modelos claros a los que imitar, pero el de ahora no. Por el contrario, lo que según Galdós domina la sociedad de finales del siglo XIX es el individuo concreto con su idiosincrasia particular, y lo que hace el arte es dibujar esos seres y acercarse a ellos en su individualidad y desde el punto de vista humano, no del de su clase social. La literatura, pues, ha de ser mimética, y la buena literatura lo es. Pero a la altura de 1897 no puede ser fiel reflejo de la sociedad dividida en los dos grupos sociales de antaño porque esto ya no existe. En su lugar lo que domina es una sociedad híbrida y por lo tanto indiferente a los matices. Por eso lo más interesante para Galdós, lo verdaderamente peculiar y matizable, son los individuos concretos, y de ésos hay muchos, e inolvidables, en sus obras. En este sentido el novelista canario se muestra como antecedente claro de la obra de autores como Unamuno, Baroja o Azorín, en la que domina la imagen del individuo enfrentado a su propio conflicto.

Pero no podemos abandonar el problema de las relaciones entre la realidad y la ficción sin observar cómo lo reflejó Galdós en sus ensayos anovelados, donde en términos generales lo analiza por medio de la acción misma. El narrador-protagonista de "La novela en el tranvía" tiene también un concepto mimético de la literatura, hasta el punto de confundir la realidad y la ficción. Pero además, y lo que es más grave, llega a inventarse a los personajes, a crearlos, después de leer un fragmento de un folletín y de ver a los

${ }^{8}$ El relato se publicó por primera vez en los números 46 y 47 de la revista La Ilustración de Madrid, los días 30 de noviembre (pp. 343 y 346-347) y 15 de diciembre de 1871 (pp. 366-367). Para información sobre otras ediciones posteriores vid. Peñate Rivero, 2001: 397-398, nota 2. 
viajeros reales del tranvía. Éste es un ejemplo, también mostrado de forma activa, del daño que la mala literatura puede causar en los lectores, un caso que cabría situar junto a los de don Quijote y Emma Bovary. Como afirma el mismo personaje-narrador:

Yo, que he leído muchas y muy malas novelas, di aquel giro a la que insensiblemente iba desarrollándose en mi imaginación por las palabras de un amigo, la lectura de un trozo de papel y la vista de un desconocido (en Mainer, 2004: 83-84).

El viajero, por lo tanto, se imagina situaciones que cree reales animado por lo que lee continuamente en los folletines, a los que es tan aficionado. La primera discordancia se debe a su afición a ese tipo de literatura, que le lleva a confundir realidad y ficción. La segunda, más grave y vinculada también a su entusiasmo por los folletines, radica en que esa inclinación desmesurada le ha trastornado el entendimiento y le impide observar la realidad tal como es. Al principio él es capaz de percibir la inverosimilitud de los folletines, e incluso de lo que él mismo inventa al hilo de aquéllos, pero llega un momento en el que hasta lo más extraño le parece posible, y ya es incapaz de razonar con coherencia. Su percepción de la realidad, mediatizada por la literatura folletinesca, es incorrecta, y de esta enfermedad sólo se cura tras meses de reposo. Lo curioso es que después decide escribir el relato con la intención implícita de que sirva de ejemplo a otros que pudieran encontrarse en una situación parecida. Una vez más, y como sucede en estos cuentos ensayísticos, el mensaje se muestra por medio del contenido mismo. Así, la literatura de folletín sólo busca distraer y deleitar al lector, como decía Galdós en "Observaciones sobre la novela contemporánea en España”, pero su propia literatura, según se refleja en "La novela en el tranvía", logra a un tiempo la máxima horaciana de enseñar y deleitar. El deleite, está claro, se consigue gracias a la compleja trama urdida por el autor, en la que curiosamente se juega con el contenido folletinesco. Pero además, y lo que es más significativo, la enseñanza se logra también de forma activa cuando se le muestran al lector las nefastas consecuencias de una afición desmesurada a la literatura de folletín, y que no son otras que la pérdida del juicio.

Si en los artículos y discursos Galdós expone de forma abierta su teoría poética, en los ensayos anovelados o cuentos ensayísticos se observan sobre todo modelos o técnicas que el novelista canario utiliza en sus grandes textos de ficción, al hilo de los cuales, además, surgen las reflexiones sobre su propia poética. En este sentido ya se ha analizado el problema de las relaciones 
entre la realidad y la ficción, así como la finalidad de la literatura en "La novela en el tranvía". Pero además, en estos cuentos la realidad narrada se proyecta desde la ironía, que es la orilla desde la que observa el autor y el mejor modo, por el humor que lleva implícito, de conseguir la enseñanza que se busca. Así, en "Un tribunal literario" Galdós trata de forma irónica los tópicos de las literaturas romántica y naturalista, pero tampoco deja títere con cabeza cuando se trata de poner en solfa la actitud de tipos concretos como autores y críticos. Los personajes, entonces, se vuelven ridículos, son meras caricaturas que representan todo aquello que quiere combatir el autor: la melosidad excesiva, la dureza extrema, la falsa erudición, la pedantería huera... La situación termina en una auténtica batalla campal que convierte la casa del autor-narrador-protagonista en un campo de Agramante del que nadie sale indemne. Esta referencia cultural, expresa en el texto, da cuenta, además, del caudal literario de Galdós. Remite al Quijote, texto presente en toda la obra del novelista canario ${ }^{10}$, concretamente al capítulo XLV de la primera parte ${ }^{11}$, pero también al Orlando Furioso de Ludovico Ariosto, donde Agramante es el nombre del caudillo de las tropas árabes que cercaron en París a Carlomagno.

Si en "Un tribunal literario" la ironía -y la crítica que ella implica- se vierte sobre la literatura, los autores y los críticos, en "El artículo de fondo" 12 ésta afecta al periodismo, y sobre todo a las formas y clichés que se emplean en el género. El texto, que debe mucho a los que escribiera Larra, es una crítica acerba contra la falta de calidad de la prensa, derivada en muchos casos de las prisas ante la diaria necesidad de rellenar el espacio en blanco. Pero además, la ironía de Galdós en este texto se dirige también hacia los tópicos, frases hechas y clichés utilizados en el periodismo, que convierten los artículos en recipientes vacíos de contenido, escritos con un lenguaje hinchado, estereotipado e insincero.

Otra característica de los relatos es su carácter metaliterario, lo que con-

${ }^{9}$ Como señala Julio Peñate (2001: 301), "el texto apareció en cuatro entregas sucesivas, del 17 al 20 de enero de 1871 en la sección 'Variedades' de El Debate, con el título de Una especie de novela y sin firma. Al año siguiente se publica de nuevo en el volumen XXVIII de Revista de España (pp. 247-267), con el título, desde entonces definitivo, de Un tribunal literario, y firmado por B. Pérez Galdós". Para otras ediciones posteriores, vid. pp. 301-302, nota 2.

${ }^{10}$ Sobre la huella de Cervantes en Galdós, Rubén Benítez compuso un trabajo fundamental en 1990 titulado Cervantes y Galdós. Literatura española e intertextualidad.

${ }^{11}$ El que lleva por título "Donde se acaba de averiguar la duda del yelmo de Mambrino y de la albarda, y otras aventuras sucedidas, con toda verdad".

${ }^{12}$ El texto se editó por primera vez en el volumen XIX, número 75, de la Revista de España, en abril de 1871, pp. 427-440. Para más información sobre ediciones posteriores, vid. Peñate, 2001: 326 , nota 2 . 
viene perfectamente a unos textos que utilizan la literatura para elaborar una reflexión sobre la misma en sus múltiples facetas. En "Un tribunal literario" se trata de uno de los rasgos más destacables del texto. Aquí el autor-narrador-protagonista ha citado a cuatro críticos para hacerles una lectura privada de una novela suya sobre la que espera recabar su opinión, novela que se va insertando, entrecomillada, en el discurso del propio narrador, entreverada con la descripción de los diferentes personajes y con la narración de las reacciones que la lectura va suscitando en los críticos. En el texto, pues, existen diversos niveles de realidad y diferentes niveles diegéticos, todo ello para exponer, desde la literatura, el concepto literario del propio Galdós, cuya figura, naturalmente, se sitúa fuera de la diégesis. En "El artículo de fondo" aparecen varios discursos: el artículo (entrecomillado) que está escribiendo el periodista; el discurso del narrador omnisciente, que es el principal, al que se supedita todo lo demás (el diálogo entre el periodista y el amigo, el artículo entrecomillado, los comentarios del autor sobre lo que sucede...), e incluso una carta de la novia. Como se puede observar, la complejidad aquí es extraordinaria. El texto, a medio camino entre el cuento ficcional y el relato de costumbres al más puro estilo larriano ${ }^{13}$, se inicia in medias res, y al mismo tiempo utiliza una técnica ya empleada en el Quijote, la de detener el relato de forma expresa ${ }^{14}$. En el caso de Cervantes, el narrador deja a don Quijote y al vizcaíno con las espadas en alto para presentar al narrador ficcional. Algunos años después, Baroja, gran lector de Galdós, emplea el mismo recurso cuando en Silvestre Paradox (1901) hace que el "autor" interrumpa el relato para exponer sus problemas en la búsqueda de

${ }^{13}$ La sombra de Larra está presente a lo largo de todo el relato, y aparece de forma expresa cuando al presentar al amigo que visita al periodista, se dice de él que "tenía la mala costumbre de insinuarse dando grandes espaldarazos y pellizcos" (en Mainer, 2004: 66). La caricaturización de este personaje es paralela a la de "El castellano viejo", donde también se habla con exageración del saludo del protagonista: "¿qué sensación no debería producirme una horrible palmada que una mano [...] vino a descargar sobre uno de mis hombros [...]?" (Larra, 1984: 178). Francisco Umbral, profundo conocedor de Larra, establece conexiones entre éste y Galdós. A su juicio, el novelista canario aprendió de los costumbristas a conocer al pueblo de Madrid, "y entre los costumbristas, Larra, que no es tal y precisamente por no serlo, resulta el único con incisión y, por supuesto, el más dotado literariamente para recrear aquel mundo. ¿Dónde sino en la crónica de Larra había visto Galdós un zapatero madrileño de portal antes de venir a Madrid?” (Umbral, 1965: 118-119). Pero Galdós no sólo aprendió en Larra cómo era el pueblo de Madrid en su entraña, sino también el arte de la caricatura, de la deformación, de la ironía, del humor y de la crítica. Y todo ello se pone de manifiesto en "El artículo de fondo", cuyo protagonista, no lo olvidemos, es un autor en trance de escribir para el periódico como les sucede a tantos protagonistas de los artículos larrianos.

${ }^{14}$ Dice Galdós: "Al llegar aquí el autor del artículo se paró. La inspiración, si así puede decirse, se le había concluido; y como si el esfuerzo hecho para crear los párrafos que anteceden produjera fatiga en su imaginación, se detuvo [...]" (en Mainer, 2004: 60). 
datos fidedignos sobre la vida del personaje $\mathrm{e}^{15}$. Este recurso de la interrupción introduce variedad en el relato, crea cierto grado de suspensión, es una muestra de ironía y pone de manifiesto el extraordinario poder del escritor (Riley, 1980: 672). Pero además consigue destruir la ilusión creada por el hecho ficcional, alcanzándose con ello un importante distanciamiento con respecto a la misma ficción.

Finalmente es interesante destacar cómo en "El artículo de fondo" el título remite al género que está utilizando el periodista en su escritura, lo que supone un claro ejemplo de metaliteratura:

Por todos estos campos, cerros, y collados corría complaciente y alborozada la imaginación del autor del artículo de fondo, cuando interrumpido el hilo lógico de éste, $[\ldots]$ ocuparon su mente $[\ldots]$ las intrusas ideas de que se ha hecho mérito (en Mainer, 2004: 61) (cursiva en el original).

El inicio del texto in medias res antes mencionado es común a otros cuentos-ensayo como "Un tribunal literario" y "La novela en el tranvía”. En todos los casos se consiguen principios sorprendentes que obligan al lector a permanecer atento y preguntarse por el hecho ficcional, y que lo introducen sin preámbulos en el núcleo de la cuestión. En el último relato citado lo que se inicia in medias res es el fragmento de un folletín recogido en un trozo de periódico con el que se envuelven unos libros. Se trata de un texto que no tiene principio ni fin, y supone el inicio de la confusión de realidades (se parece a una historia que acaban de contarle al viajero-narrador) que está en el centro de la complejidad del texto. Aquí el recurso muestra la inconsistencia y la falta de lógica de unas historias (las de los folletines) que pueden empezar por cualquier parte y ser continuadas ad infinitud por cualquier autor de mente calenturienta. En el texto, además, se pone de manifiesto el paralelismo entre la vida y la literatura porque las dos historias (la narrada en el folletín y la que cuenta el médico) son idénticas. De este modo regresamos al principio para plantearnos, de nuevo, el asunto de la mímesis en la teoría poética del novelista canario, y para preguntarnos si es la literatura de folletín la que imita a la vida intentando parecerse a ella. La respuesta es sencilla, y revela cómo la idea que Galdós tenía sobre el origen de la literatura se mantuvo idéntica desde el principio hasta el final de su trayectoria, y cómo fue expresada de la misma forma en textos ensayísticos y en ensayos

\footnotetext{
${ }^{15}$ En el capítulo IV el personaje de Silvestre niño es abandonado en París, de noche y sin dinero, mientras el "autor" reanuda sus investigaciones intentando conseguir información.
} 
anovelados. Para él la novela de folletín no imita la realidad del hombre contemporáneo y por lo tanto no entra en la categoría reservada a la buena literatura. El folletín crea una realidad propia e inexistente, y sólo cumple con la finalidad de entretener y deleitar, por lo que, y dado además su mal ejemplo para la juventud, es un género nocivo que debería ser desterrado. Por si esto fuera poco, además, la lectura del género puede provocar daños severos en la salud, como pone de manifiesto la locura del narrador viajero de "La novela en el tranvía". Así, para Galdós existe una relación evidente entre el folletín y los libros de caballerías, lo que supone un nuevo elemento que permite vincular al autor del Quijote con el de Fortunata y Jacinta ${ }^{16}$. En este sentido Alan E. Smith, al referirse al elemento metaficcional en ambos autores, afirma con razón que éste implica tanto en Galdós como en Cervantes una ideología, es decir, "una epistemología y una actitud ante la historia" (Smith, 1992: 68), lo que significa, en el fondo, que ambos comparten un mismo sentido moral del hecho literario. $Y$ esto es siempre digno de destacar, sobre todo en tiempos de crisis de valores como los actuales.

\section{REFERENCIAS}

Alas, Leopoldo. 1912. Galdós, Madrid: Renacimiento.

Aristóteles. 2002. Poética. Edición de Antonio López Eire. Madrid: Istmo.

Benítez, Rubén. 1990. Cervantes y Galdós. Literatura española e intertextualidad. Murcia: Universidad de Murcia.

Bonet, Laureano. 1999. Ensayos de crítica literaria. Benito Pérez Galdós. Barcelona: Península.

Larra, Mariano José. 1984. Artículos. Edición de Enrique Rubio Cremades. Madrid: Cátedra.

Mainer, José Carlos. 2004. Introducción y edición a Prosa Crítica. Benito Pérez Galdós. Madrid: Espasa Calpe.

Peñate Rivero, Julio. 2001. Benito Pérez Galdós y el cuento literario como

${ }^{16}$ Julio Peñate Rivero (2001: 418) se refiere a la huella del Quijote en "La novela en el tranvía" con estas palabras: "En este relato se puede observar que dicha huella es particularmente profunda, como lo muestra la locura del protagonista por leer muchas y malas novelas seguido de su cordura final, la atribución de falsa identidad a personajes (si en El Quijote [sic] las ovejas son un ejército, princesas las prostitutas y gigantes los molinos, aquí un comerciante honrado es un malvado asesino, héroe de ficción un joven normal y conspirador un cazador apenado por la muerte de su perra), la presencia de viajes imaginarios (el Clavileño cervantino acaso reencarnado en el tranvía volante), el sentido común de Sancho finalmente representado por la turista inglesa y el deseo de deshacer entuertos imaginarios tanto en el ingenioso hidalgo como en el justiciero lector de folletines". 
sistema. Lausanne: Sociedad Suiza de Estudios Hispánicos.

Pérez Galdós, Benito. 1870. "Noticias literarias. Observaciones sobre la novela contemporánea en España”, en J. C. Mainer (ed.), Prosa crítica. Benito Pérez Galdós. Madrid: Espasa Calpe, 2004, pp. 10-26. . 1871. "Un tribunal literario", en J. C. Mainer (ed.), pp. 32-60. pp. 74-97. . 1871. "La novela en el tranvía", en J. C. Mainer (ed.), pp. 60-74. . 1871. "El artículo de fondo", en J. C. Mainer (ed.), . 1897. "La sociedad presente como materia novelable”, en J. C. Mainer (ed.), pp. 105-113. . 2002. El crimen de la calle de Fuencarral. Ediciones Lengua de Trapo: 1888.

Riley, Edward C. 1980. "Literatura y vida en el Quijote", en Historia y critica de la literatura española, II, Renacimiento. Madrid: Crítica, pp. 667674.

Rivas Hernández, Ascensión. 1998. Pio Baroja. Aspectos de la técnica narrativa. Cáceres: Universidad de Extremadura.

Rivas Hernández, Ascensión. 2007. "Galdós y la crónica periodística: El crimen de la calle de Fuencarral", en Insula, 730, pp. 2-5.

Smith, Alan E. 1992. Los cuentos inverosimiles de Galdós en el contexto de su obra. Barcelona: Anthropos.

Umbral, Francisco. 1965. Larra. Anatomía de un dandy. Madrid: Alfaguara. 